\title{
LA DOCTRINA DEL SHOCK. El auge del capitalismo del desastre
}

Naomi Klein.

Paidós Ediciones, 2010, 701 pp. [Toronto: A.Knopf Ed., 2007].

ISBN 978-84-493-2345-4.

Comentario: Carlos Lange V. ${ }^{1}$

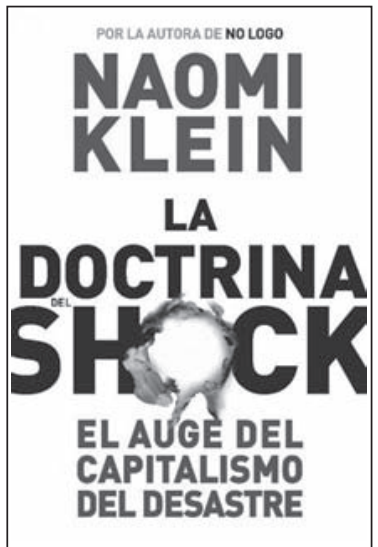

¿Qué tienen en común experiencias tan traumáticas como la invasión y posterior ocupación de Irak realizada por las tropas estadounidenses y sus aliados desde principios del 2003, el devastador tsunami que azotó las costas de Sri Lanka el año 2004 o la destrucción de Nueva Orleáns por el Huracán Katrina en 2005?

En su libro La Doctrina del Shock. El Auge del Capitalismo del Desastre, la periodista canadiense Naomi Klein postula que estas "traumáticas" experiencias, así como también otras durante los

últimos 30 años, han sido aprovechadas para instaurar lo que ha denominado como el "capitalismo del desastre", una doctrina formada bajo los presupuestos políticos, económicos y sociales desarrollados por el padre de la Escuela de Chicago, Milton Friedman, y cuyo principal objetivo es desmantelar los restos del Estado de Bienestar y promover a nivel global el modelo de desarrollo neoliberal.

A juicio de la autora, para los seguidores de Friedman, caracterizados por su marcado carácter

1 Chile. Licenciado en Antropología, Mg. en Desarrollo Urbano. Doctorando en Ciencias Sociales y Comunicación, U. de Deusto. Académico Instituto de la Vivienda, U. de Chile. Correo electrónico: clange@uchilefau.cl

revista invi № 70 / Noviembre 2010 / Volumen № 25: 225-227 225 
neoconservador, las fuerzas económicas del mercado como la oferta y la demanda, la inflación y el desempleo, constituyen fuerzas naturales, fijas e inmutables, a las cuales es necesario volver borrando todo rastro de intervención estatal que impida la consecución del libre mercado, entendido como "utopía de los emprendedores". En este sentido, el "capitalismo del desastre" postula que detrás de toda "tragedia" es posible ver una "oportunidad", como es la de aprovechar el trauma colectivo para promover e implementar reformas económicas y sociales de carácter radical sustentadas en los principios básicos del corporativismo como son la eliminación del rol público del Estado, la absoluta libertad de movimientos de las empresas privadas y un gasto social prácticamente nulo.

La implementación de este modelo debe su éxito a una estrategia política denominada como "la doctrina del shock", la cual orienta los procesos de reconstrucción implementados como respuesta tanto a los efectos de intervenciones militares como a desastres naturales de distinto tipo, abriendo "apetitosas oportunidades de negocio" a los agentes, defensores y promotores del "capitalismo del desastre".

Más que un estudio estrictamente académico, el libro de Klein constituye una documentada investigación periodística que recrea de manera detallada el largo e intrincado itinerario de maduración y reproducción del modelo propuesto por Friedman con posterioridad a la Gran Depresión del año '29, constituyéndose como una reacción crítica al éxito alcanzado por las propuestas keynesianas en EEUU, las propuestas socialdemócratas en Europa y las teorías desarrollistas en América Latina. Derivado de lo anterior, el libro analiza también la conformación de una clase política y empresarial formada bajo su ideario y agrupada en torno a la Escuela de Chicago, desde donde ha desarrollado una importante expansión hacia distintas regiones del mundo desde mediados del siglo XX hasta hoy.

Junto con lo anterior, la autora da cuenta pormenorizada de la manera como "la doctrina del shock" ha sido aplicada en distintos momentos históricos y en distintas regiones del mundo, con el objeto de imponer sus postulados de libre mercado. Dentro de dichas experiencias destaca, por ejemplo, el decisivo papel jugado por el gobierno estadounidense y la CIA en la desestabilización del gobierno socialista de Salvador Allende y el activo papel que los "Chicago Boys" jugaron para convertir a Chile en el laboratorio de su modelo político y económico, amparados bajo el terror y la coerción impuestas por la dictadura militar de Augusto Pinochet. Asimismo, la autora da cuenta también de las experiencias de shock desarrolladas bajo los gobiernos de Margareth Thatcher en el Reino Unido y de Ronald Reagan en el mismo EEUU durante la década de los '80s, de las transformaciones implementadas en Polonia, Rusia y Sudáfrica durante 
la década de los '90s, o la misma experiencia desarrollada en Irak tras la invasión del año 2003, y que tan ventajosa ha resultado en términos económicos para las empresas de servicios que han logrado adjudicarse las concesiones contempladas bajo el proceso de "reconstrucción" de dicho país.

No obstante su amplia y profusa distribución mundial desde su fecha de publicación original hasta nuestros días, el libro de Klein no pierde relevancia ni actualidad.

Por una parte, permite comprender el proceso histórico de formación de una nueva clase dirigente, los denominados "neoconservadores", y la evolución de los postulados ideológicos que sustentan su conformación, así como también sus estrategias de expansión e implementación en distintas regiones del mundo.

Por otra, constituye una invitación para observar de manera atenta, abierta y crítica los efectos de los planes y programas de reconstrucción actualmente en ejecución en sociedades afectadas por conflictos bélicos o desastres naturales, como son actualmente los casos de Haití, Chile y China, afectados por sendos terremotos, o Pakistán, India y Brasil, afectados por sendas inundaciones, entre otros. En el caso de nuestro país adquiere incluso una relevancia particular considerando su reconocimiento como laboratorio y "modelo exitoso" de las propuestas de Friedman, la profundidad con que ellas han sido implementadas por las élites políticas y económicas, y las transformaciones sociales y culturales que han generado en la sociedad chilena durante los últimos 30 años.

Por último, el libro de Klein constituye también un aporte interesante para comprender las complejidades que atraviesan los procesos de producción y construcción social del hábitat, principalmente aquellos caracterizados por altos niveles de pobreza y vulnerabilidad que afectan a su población y que son experimentados cotidianamente por sus habitantes. Bajo el entendido que pobreza y vulnerabilidad no constituyen realidades naturales, del trabajo de Klein se desprende la importancia fundamental que los actores y agentes económicos juegan en dicho proceso, de los postulados ideológicos que sustentan sus propuestas y de las herramientas que utilizan para dichos fines, enmarcándose fundamentalmente en políticas, programas y proyectos cuyos alcances no son fácilmente identificables para el conjunto de la población. 